\title{
THE SITUATION OF DIGITALIZATION OF INCLUSIVE EDUCATION AND THE PROBLEMS IN ARMENIA
}

\author{
AUTHORS' DATA \\ Samvel Asatryan, $\mathrm{PhD}$ in Education, Associate Professor \\ Chair of Informative Technologies \\ Khachatur Abovyan Armenian State Pedagogical University, Republic of Armenia \\ Contacts: asatryansamvel06@aspu.am
}

\begin{abstract}
There is no doubt to state that the 21 st century is the century of digital information and endless technological possibilities. A century when thousands of new high-tech mechanisms are being created at an incredible speed, the main goal of which is the most comfortable and convenient life for people. Digital technologies have filled almost all spheres of human life and activity. Today, a large number of countries in the world have a successful experience in the introduction and use of digital technologies in education. Undoubtedly, they play a special and important role in the education of people with disabilities, the disabled and people with special needs.
\end{abstract}

The exercise by persons with disabilities of the right to education, a fundamental human right, is fraught with several challenges. The lack of necessary conditions for full participation in the educational process that meet the individual needs and abilities of students, as well as the use of insufficiently effective teaching methods, leads to the fact that the youngest people with disabilities cannot get a good education and profession. The inaccessibility of education is one of the main reasons preventing the full inclusion of disabled people in the life of modern society.

Results of the study indicate that the correct use of the capabilities of modern digital technologies by the teacher will contribute to effective work to overcome violations of psychophysical development.

Key words: digitalization, digitalization inclusive education, technological possibilities, digital transformation of education, e-inclusion, motivation for learning activities.

\section{LITERATURE REVIEW}

The problem of barrier-free access to education is of particular importance in the light of the entry into force of the UN Convention on the Rights of Persons with Disabilities, which 
indicates the need to ensure the availability of "information and materials in the field of education and training for all children" (Convention on the Rights of Persons with Disabilities Conventions and agreements - Declarations, conventions, agreements and other legal materials, 2006)

The creation of suitable learning environments for students with disabilities can be achieved through the use of the potential of information and communication technologies. Information and communication technologies allow not only optimize the educational process, increase the availability of educational resources, but also create the necessary prerequisites for the assimilation of knowledge, the activation of creative abilities and the development of a holistic worldview of the individual. Modern information technologies provide disabled people with unique opportunities to receive information, communicate, and carry out research activities, which they were deprived of from birth due to natural disasters, military conflicts or human violence.

Armenian teachers consider the digital transformation of education (DET) to be an inevitable process, including a change in the content, methods and organizational forms of educational activities, unfolding in a very rapidly improving and developing digital educational environment. In their opinion, this process is aimed at fulfilling the tasks of the country's socioeconomic development.

Recently, the new term e-inclusion has been added to the concept of inclusion. Einclusion is the use of digital technologies, which is a complex of technical devices and information and communication technologies (ICT) in the formation of inclusive education (Handbook of Research on ICT-Enabled Transformational Government: A Global Perspective, 2011).

The digital transformation of inclusive education was studied by such scientists as Alyokhina S.V. (Alyokhina S.V., 2013), who presents the difficulties of organizing inclusive education in the modern world developing more than 10 point guidelines to help young teachers organize inclusive lessons. Khukhlaev O.E., Chibisova M.Yu. (Khukhlaev et al., 2015) referred to an inclusive approach to the integration of migrant children in education, which is one of the problems of the modern world - the organization of inclusive education in the conditions of active migration flows. The analysis of Shemanov A.Yu. (Shemanov, 2016) deserves special attention. This paper discusses the application of digital technologies in the development of inclusive education from the point of view of collisions between individual and social models of inclusion, technological determinism and contextual approach. It examines the range of approaches to educational integration. Following K. Abbott, it examines three areas of research of digital technologies (concerning training and repetition, supporting the educational 
process and creating learning opportunities). It also regards the place of each approach to the development of inclusion in education. In conclusion, it discusses the problems and perspectives of development of this area of research and development.

The relevance of the study of this topic, no doubt, is determined by its social significance. The number of children with disabilities in the world is almost 240 million, according to a new UNICEF report. Children with disabilities, in contrast to children without disabilities, are in a more unfavorable position when it comes to calculating child welfare criteria.

Also, the relevance of the topic is due to 2 main reasons. The first reason is because of the rapid development of digital devices and information and communication technologies, i.e. digital technologies, greatly change the behavior and lifestyle of a person, including in the learning process. The second, and most important, reason for the relevance of studying this topic is that, despite the active use of digital technologies in the field of education, the concept of using digital technologies in inclusive education remains underdeveloped. When we talk about e-inclusion, it is very important not to oppose general and inclusive education, but to consider the latter as a way of a general reformation of the former, in line with the concept of expanding social inclusion in general.

\section{ANALYSIS OF THE CURRENT SITUATION IN ARMENIA}

The Republic of Armenia declares universal inclusive education as a guarantee of ensuring the right to education of every child. The inclusive education policy is aimed at ensuring the quality of access to education for every child, the opportunity for equal participation.

On December 1, 2014, the RA National Assembly adopted the RA Law on Making Amendments to the RA Law on General Education (HO-200-N), which envisages the transition to universal inclusive education in the general education system. According to the law, the system of universal inclusive education will be introduced in the republic by August 1, 2025.

Teacher assistant positions will be introduced in the state secondary schools of the Republic of Armenia, the number of which will be determined by the ratio of $10 \%$ of the average annual number of students in the given school, according to the procedure approved by the RA Government (ESCS, 2017). The system of universal inclusive education will be introduced by August 1, 2025, according to the action plan ll schedule approved by the Government of the Republic of Armenia.

If observance and execution of these legislative acts are ensured, then, in the end, society will come to understand that "inclusive education is a step towards achieving the ultimate goal creating an inclusive society. 
Both foreign and our experience shows that joint education of children with disabilities (children with disabilities) and healthy children is quite effective, however, despite this, inclusive education experiences several difficulties and problems. The most important problem of inclusive education is the lack of qualifications and special training necessary for teachers. Teachers in ordinary schools, as a rule, do not have the necessary skills and abilities to involve a special child in the educational process. To solve this problem, it is necessary to organize the work of tutors in schools. A tutor is a person who has special education and is exempt from teaching lessons. Inclusive education tutors are needed to carry out a dialogue between teachers and experts who have the necessary skills in this area, as well as to improve the skills of teachers through webinars, lectures, etc.

Of course, the problem of insufficient funding of organizations that implement inclusive education is of great importance. For children with disabilities to be able to study without difficulty in ordinary schools, special technical equipment is needed. For deaf and hard of hearing children - electro-acoustic equipment, for children with disorders of the musculoskeletal system - ramps, elevators, an automatic door opening system, personnel call buttons, etc., for children with visual impairments - a sound informant, contrast and tactile markings, etc. Also, it is necessary to create rooms for therapeutic physical culture, rooms for classes with a speech therapist, psychologist, speech pathologist.

Another problem in the implementation of inclusive education is the non-recognition of children with disabilities by people. We are talking, first of all, about the unwillingness of parents of healthy children to conduct training together with children with disabilities. It seems to them that this will reduce the quality of education, and care for a child with health problems will be carried out to the detriment of care for other children. To combat these stereotypes, it is necessary to conduct medical and psychological education of the society.

To solve these problems, it is necessary to develop a set of measures for the development of joint education of children. To do this, it is necessary to improve the legal framework, material, technical and staffing of this process. For people with disabilities to receive a fullfledged education, assistive technologies are being developed and applied (ICT in inclusive education) which are devices aimed at providing comfortable conditions in everyday life.

Even though the ways of using ICT in the inclusive education of people with disabilities are extremely diverse, the following main areas of their use can be distinguished:

1. Application of ICT for solving compensatory problems. The use of technology as an assistive device allows students with functional limitations to take an active part in the learning process. For example, in the case of visual impairments, technologies make it possible to perceive information through hearing or touch, and in the case of impaired 
motor function of the hands, they allow the student to enter text on a computer. In other words, technologies help compensate (compensate) for the lack of natural body functions and, thus, optimize the process of obtaining information, and also create conditions for the assimilation of knowledge.

2. The use of ICT for solving correctional problems. The use of ICT significantly increases the possibilities of the correctional and educational process in such areas as diagnosing and monitoring the development of knowledge, skills and abilities of students; restoration and replacement of lost or impaired functions. The technology used to educate students with disabilities has significant potential to enrich their life experiences.

3. The use of ICT for solving didactic problems. The use of ICT as a didactic tool contributes to the maximum realization of the intellectual and creative potential of students, creates conditions for the application of modern teaching strategies and knowledge control. In addition, to meet the educational needs of students who are unable to attend regular school classes, ICTs are often used as a means of distance learning.

4. Application of ICT for solving communication problems. Technologies act as intermediaries in the process of communication, and sometimes even are the only way to communicate with the outside world. For each category of users experiencing difficulties in the communication process, special assistive devices and software are being developed.

The main problems that students with motor disabilities have are related to the use of the keyboard and mouse to enter text and control the computer. To prevent simultaneous pressing of several keyboard buttons in case of motor impairments of mild and moderate severity, it is recommended to use specialized overlays placed over the standard keyboard and facilitate access to the keyboard buttons. To facilitate computer management, the capabilities inherent in the Access Windows program are widely used: control over response time and repetition of commands, control of a combination of buttons responsible for special commands and functions, control of the mouse cursor through the numeric keypad on the keyboard.

In case of severe movement disorders, alternative keyboards are used. Larger keyboards facilitate selection and precision with fewer buttons and larger buttons than a standard keyboard. Keyboards with small and closely spaced buttons are used in cases where the user cannot perform large movements and is prone to fatigue. In some cases, touchpads are used that have a touch-sensitive surface, which is divided into programmable areas. Speech recognition 
technology provides the user with the ability to both control the functions of the operating system and enter text using voice.

To facilitate the manipulation of students with movement disorders, various types of pointing devices are used. The user makes his choice with suitable devices having various shapes, sizes and levels of sensitivity; they can be activated by hands, feet, head, short and strong exhalation, voice, muscle movements, and in other ways, depending on the user's capabilities (see Table 1).

\section{Table 1.}

Devices designed to facilitate the manipulation of students with motor disabilities.

\begin{tabular}{|l|l|}
\hline \multicolumn{1}{|c|}{ Device/program name } & \multicolumn{1}{|c|}{ Device/program characteristic } \\
\hline Manipulator TrackBall & $\begin{array}{l}\text { Changing the position of the ball causes the } \\
\text { cursor to move on the screen, such devices are } \\
\text { equipped with programmable buttons. }\end{array}$ \\
\hline Touchpad & $\begin{array}{l}\text { It has a flat, tactile surface, mainly used in } \\
\text { notebooks, but can also be used on desktops. }\end{array}$ \\
\hline Joystick & $\begin{array}{l}\text { Moving the lever in different directions allows } \\
\text { you to control the cursor on the screen, the } \\
\text { system control functions using the joystick } \\
\text { may differ depending on the user's functional } \\
\text { needs. }\end{array}$ \\
\hline Electronic pointing devices & $\begin{array}{l}\text { They allow a person to control the cursor on } \\
\text { the screen without the help of hands, cursor } \\
\text { control is carried out using ultrasound, } \\
\text { infrared rays, muscle contractions of the } \\
\text { hands, eye movement, nerve impulses, and } \\
\text { also waves emitted by the brain. }\end{array}$ \\
\hline Touch screen & $\begin{array}{l}\text { The device is equipped with a special surface } \\
\text { on the outer part of the screen that is sensitive } \\
\text { to touch and performs all the functions of a } \\
\text { mouse. }\end{array}$ \\
\hline
\end{tabular}

GoTalk speech simulators are actively used in the world. They are devices for people to communicate and are needed to master, develop or restore speech skills on their own or with the help of a specialist. This tool has a voice recorder necessary for recording and subsequent playback of the recordings made. A recording can consist of a single sound or whole sentences. As a result, what has already been learned can be deleted or left on the device, gradually supplementing with new entries. This device is also used for the rehabilitation and simplification of communication between adults after a serious illness.

For students with language and speech impairments due to severe intellectual, somatic, neurological or neuropsychological disorders, Augmentative Alternative Communication (AAC) systems are a means of communicating with others (Sigafoos, J. \& O'Reilly, M.F. 
2004). The use of alternative communication systems is based on the use of a different way of encoding information, different from speech. Depending on the needs of the user, alternative communication systems can use photographs, diagrams, drawings and symbols, including handwritten ones.

The use of alternative communication systems is based on the use of a different way of encoding information, different from speech. Depending on the needs of the user, alternative communication systems can use photographs, diagrams, drawings and symbols, including handwritten ones (ISAAC - Home, n.d.).

A special place among high-tech means of communication is occupied by auxiliary communicative scoring devices (Voice Output Communication Aid, VOCA). In size, such devices, as a rule, are no larger than an ordinary notebook, they are equipped with special buttons or special fields, the impact of which leads to the reproduction of recorded words or short phrases. Most assistive communication devices use so-called digitized speech, that is, the human voice recorded in the device's memory.

The computer can be an excellent means of motivation for learning activities for students with intellectual disabilities, which is associated with the desire to imitate adults. However, the use of a keyboard and mouse to control a computer can present serious difficulties for such students due to slow and inaccurate hand-eye coordination, difficulty in perceiving and identifying a stimulus, as well as memory and attention disorders. To overcome these difficulties, various devices and programs are used to make it easier for users to access and control a computer. Among the input devices, one can note the use of various types of keyboards, manipulators and positioning devices.

The increased complexity of the software interface (quality and type of text, graphics, sound, feedback principles, etc.) can create difficulties for mentally retarded students. The background of the program, overloaded with illustrations and saturated with various colors, interferes with orientation on the screen and is unsuitable for such categories of users. For this reason, it is recommended that you choose and configure your software carefully.

Despite individual differences and the capabilities of users with intellectual disabilities, it is recommended to avoid a large number of icons on the computer desktop, as well as background images. Depending on the needs of the user, the shape and size of the cursor, its color, and contrast can be adjusted. In addition, the combination of many stimuli during the actualization of the same object (that is, the demonstration of the image itself, the sound signals, and the written designation of this object) can contribute to the process of its recognition. 
The needs of people with visual impairments for assistive technology depend on the degree of loss of visual function. Visually impaired students need help in using the available visual possibilities in the most rational way, as well as in mastering new technical means and methods of communication through other modalities. Students with complete visual loss need help using technical communication tools in the auditory and tactile modalities.

Visual information is often organized in such a way that it is extremely difficult to use the cursor. Text-to-speech programs or text-to-speech programs and speech synthesizers may sound the label found in some images, which can be disorienting to the user. To make it easier for blind users to work with a computer, a sequence of bookmarks can be used to help determine the position of the mouse cursor on the screen. Another approach involves a combination of voice and tactile information output based on the use of a tactile panel that allows you to "touch" the position of the cursor on the screen, to feel when it passes through menu options or hyperlinks (Convention on the Rights of Persons with Disabilities Conventions and agreements - Declarations, conventions, agreements and other legal materials, 2006).

To teach and improve typing for students with visual impairments, buttons should be specially labeled (as is commonly used on a standard keyboard) so that the user can enter text using the ten-finger typing method. It is very effective to use special programs that make it easier to check the text and correct errors in it. In this case, programs that support the Braille system can be used.

The Duxbury Braille Translator (DBT) program, which performs bidirectional translation, has also found active use: a regular font is translated into Braille and vice versa. In addition, Duxbury Braille Translator has a complete set of functions with which you can prepare a document for Braille printing in a huge number of languages and a wide variety of encodings. DBT features are:

1) Ability to import files in MS Word, WordPerfect, HTML format.

2) Ability to create text directly in the DBT editor.

3) Ability to enter text in plain or Braille.

4) The program contains a huge number of "formatting keys", that is, functions that allow you to select the desired file format. When creating various combinations of formatting keys, corresponding styles are created that make working with text easier. Basic styles are already included in the program, but the user can create his own. It is also possible to create style templates in the program for further use when creating new documents.

5) The program includes a spelling dictionary consisting of three hundred thousand words. 
6) There is a "Quick Find Misspelling" function that quickly detects spelling errors and immediately eliminates them.

7) This program can support almost all available models of braille printers.

Digital technologies are of great importance in overcoming educational and social barriers, as they have become familiar everyday tools for performing elementary tasks in inclusive education. An example is the maintenance of a classroom blog, which creates a certain platform for equal communication of all students in the class as a whole, and those students for whom communication at school is physically difficult. The use of different learning platforms makes it possible to track the progress of each student because this is very important when children with different educational needs study in the same class.

Currently, special software tools have been developed to support graphic activities on the computer of blind users. Such programs are based on feedback through a complex set of audio signals (Cook, 1998).

Hearing impairments, on the one hand, make it difficult or even prevent the perception of auditory information by a person, and on the other hand, do not allow you to control your own speech. Such shortcomings, in turn, lead to severe speech disorders and difficulties in mastering the norms of the language. Due to insufficient mastery of the lexico-grammatical and syntactic components of the language system, students experience serious difficulties in their educational activities (Grassman, 2002). In turn, violations of expressive and impressive speech lead to other difficulties in those areas of educational activity that are associated with the verbal function of a person (cognitive processes, logical operations, generalizations of reality in the form of abstraction, etc.). In turn, violations of expressive and impressive speech lead to other difficulties in those areas of educational activity that are associated with the verbal function of a person (cognitive processes, logical operations, generalizations of reality in the form of abstraction, etc.).

There are various approaches to using assistive technology to develop and improve the communication skills of people with hearing impairments. So, one of the approaches assumes the presence of feedback based on visual or tactile sensations. Another approach is to use various alternatives to oral communication, such as subtitles or simultaneous translation into the national sign language. Automated systems enable teachers to create audiovisual material with subtitles. Some technologies allow simultaneous translation of oral speech into written (presented on the monitor screen) and, thus, help to perceive the teacher's oral speech in the classroom. However, such systems are very expensive and their use is justified for a large group of students with hearing impairments. To improve the perception of auditory information in large rooms (for example, in classrooms), wireless auxiliary acoustic systems using radio 
frequencies, as well as infrared and induction systems, are used. Some software tools allow you to provide visual feedback that reflects some characteristics of your own spoken language (for example, tone and pitch). Such software is mainly used for rehabilitation purposes. Standard use of a personal computer and software by deaf and hard of hearing students does not require the use of special techniques in work. The possibilities of "Access Windows" allow, in some cases, to transform sound prompts into visual ones, thanks to the actualization of the necessary information using special characters and selected text.

To raise the issues of the use of information and communication technologies in the process of providing inclusive education in the Republic of Armenia, we have organized a social survey.

More than 80 teachers from Yerevan, who provide inclusive education, took part in the social survey. Present the results .

\section{Question 1.}

\section{Do you use ICT in an inclusive course?}

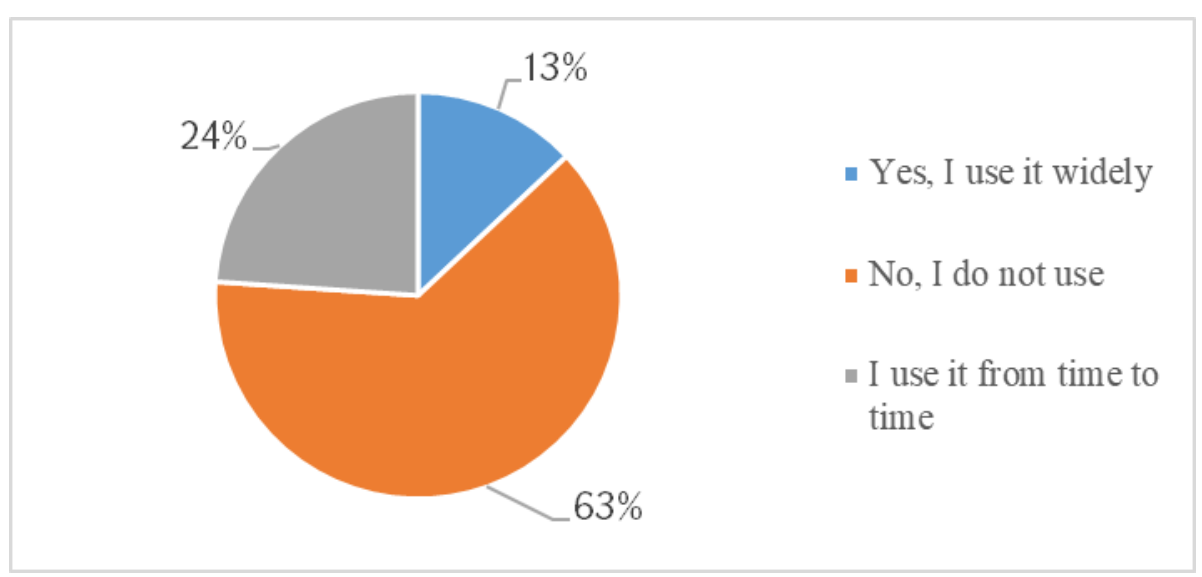

$13 \%$ of the surveyed teachers state that they actively use ICT in their teaching process. In private conversations, they argued that ICTs help teachers to include children with special educational needs in the classroom, making the learning process person-centered. They note that specialized computer programs open a wide field of opportunities for teachers and students, but at the same time, they state that today such software resources are limited. $63 \%$ of the surveyed teachers mentioned that they do not use ICT tools during their activities. Moreover, they found that computer programs and tools were not very effective in working with children with special educational needs. And $24 \%$ of the participants mentioned that from time to time they use technological means. In particular, this group of surveyed teachers mostly mentions the Youtube video database, which allows them to watch videos with different content, use them in different stages of learning to work with children with special educational needs. Some teachers mentioned that they use several specialized programs for speech development, which were developed on their own initiative. As a result, we can state that some 
teachers use ICT tools in their activities, but they are not systematic and universal, that is, inclusive education can not be considered digital yet.

\section{Question 2.}

What types of specialized software and hardware (assistive technologies) exist in your organization?

\begin{tabular}{|l|c|}
\hline Braille display & $3 \%$ \\
\hline Speech synthesizer & $2 \%$ \\
\hline Braille printer & $0 \%$ \\
\hline Speech recognition programs & $4 \%$ \\
\hline Built-in operating system capabilities & $27 \%$ \\
\hline Voice guidance programs & $7 \%$ \\
\hline Keyboards with longer keys and increased font size & $5 \%$ \\
\hline $\begin{array}{l}\text { Special devices allowing you to control the mouse cursor with head } \\
\text { movements }\end{array}$ & $1 \%$ \\
\hline Specialized software & $16 \%$ \\
\hline Other & $35 \%$ \\
\hline
\end{tabular}

$3 \%$ of the surveyed teachers state that they have used Braille display during their professional activity. They claim that they acquired the special professional equipment and software with the help of benefactors. In this matter, they expect the state's attention. The largest number of respondents mentioned the "other" version. In private conversations, they mentioned that in the organization of inclusive learning, they use the most accessible means at that time - videos, software built-in software.

\section{Question 3.}

At what level of education, in your opinion, is there the greatest integration of ICT in the education of people with disabilities?

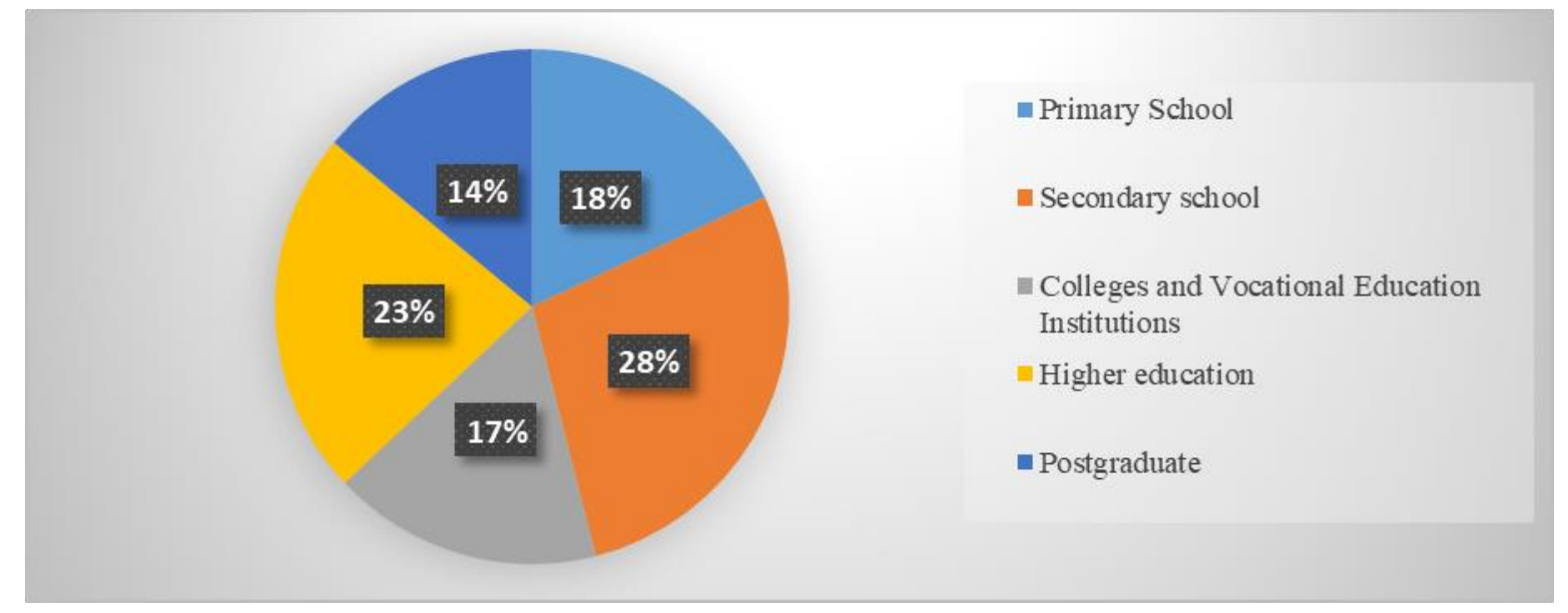


Quite an interesting picture was obtained. The participants of the survey almost equally mentioned that the use of ICTs in all levels of education is relevant and important today. This proves that it is necessary to develop a state policy and invest in the development of various specialized programs at the state level.

\section{Question 4.}

Are regular workshops and seminars held in your region (country) aimed at raising awareness and developing professional skills among teachers in the use of ICT for the education of children with special educational needs?

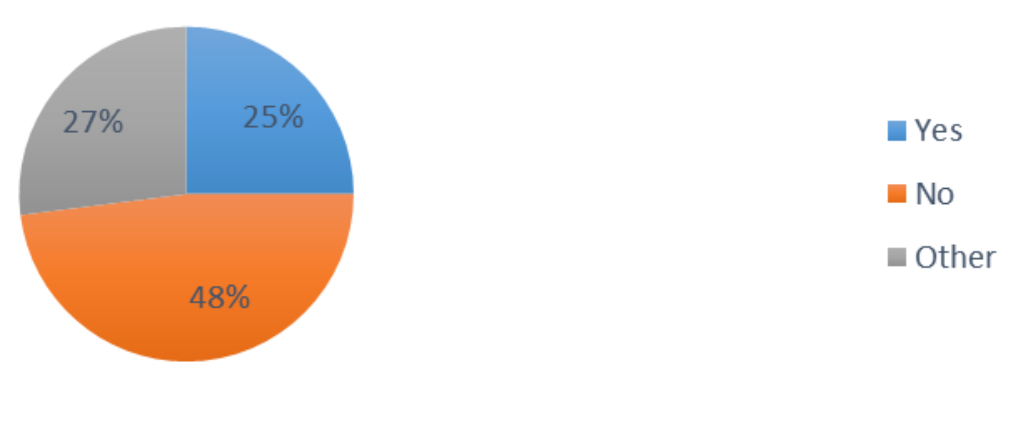

$48 \%$ of the surveyed teachers stated that they do not participate in any workshops related to the process of digitalization of inclusive education. Twenty-five percent of teachers surveyed said they had attended various seminars, workshops, and webinars related to the digitization of general education, while the remaining 27 percent said they had attended unique, non-regular events.

\section{Question 5.}

Are there conditions in your educational institution that will allow children with special educational needs to be fully involved in the learning process?

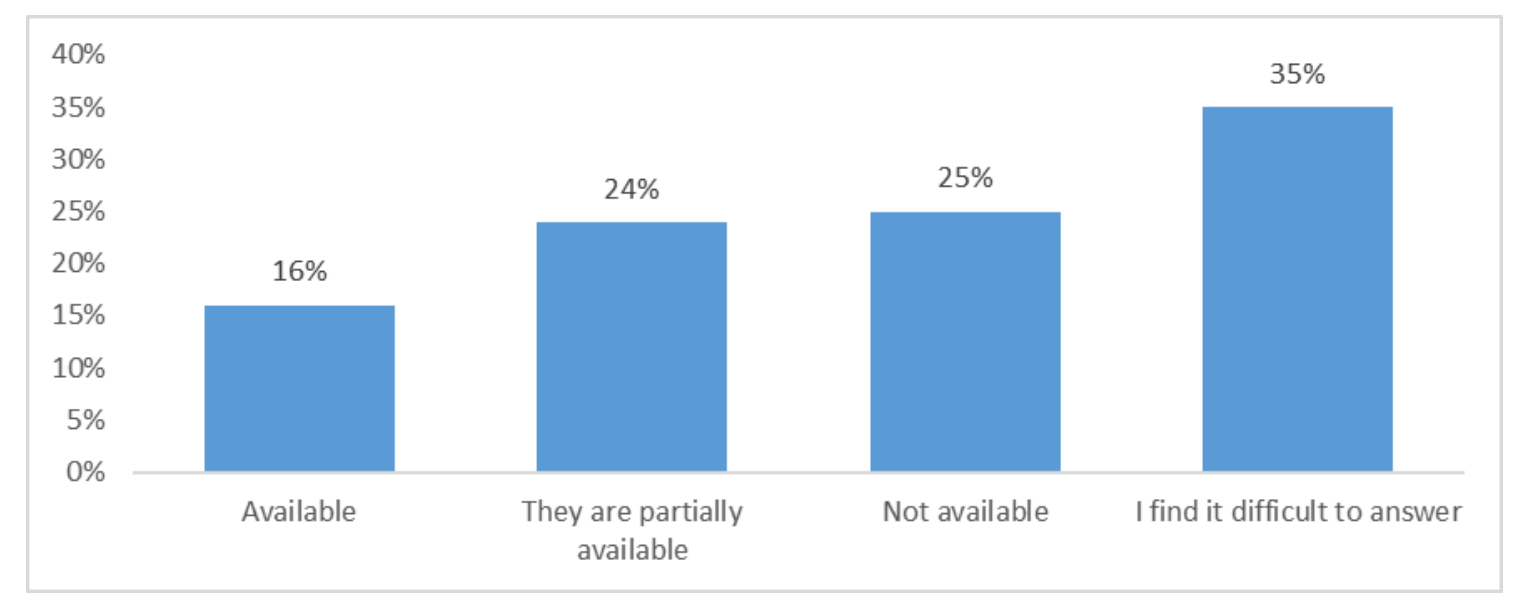


Sixteen percent of those surveyed said that their school has access to technologies that allow the teacher to fully include children with special needs in the learning process, and 24 percent said partly because the use of ICTs in their school is not universal. 1/4 of the respondents stated that they do not have access to ICT tools to implement inclusive education effectively.

\section{CONCLUSION}

Detail of the application of distance form training, when working with ice cream with special educational needs, made in the first instance of completing such a task as the formation of necessary conditions for the completion of full education without any hardships and limitations, provision of guarantees for individual education based on inclusive income. I note that the fact that half of the full-fledged barbaric education of people with limited health benefits is, in its view, a pledge of successful socialization.

The process of formation of inclusive education, the transformation of its system and content is still relevant today. Providing educational institutions with modern technical equipment is a mandatory part of the modernization of the educational environment in the organization of an inclusive process, ensuring its accessibility for children and adults with different needs and individual developmental characteristics.

The correct use of the capabilities of modern digital technologies by the teacher will contribute to effective work to overcome violations of psychophysical development, and the improvement of the technical capabilities of digital technologies will allow addressing the problems of successful learning and adaptation in a social society, taking into account the needs of each person with disabilities.

\section{REFERENCE LIST}

1. Alyokhina S.V. (2013). Inclusive education: history and modernity: teaching aid. Pedagogical "Eniversity of "First September." http://school30.org.ru/docs/Ped_soveti/ped_sovet_7_30_12_15/inkluz_obr_istoriya.pdf

2. Convention on the Rights of Persons with Disabilities - Conventions and agreements Declarations, conventions, agreements and other legal materials. (2006, December 13). Convention on the Rights of Persons with Disabilities. https://www.un.org/ru/documents/decl_conv/conventions/disability.shtml

3. Convention on the Rights of Persons with Disabilities - Conventions and agreements Declarations, conventions, agreements and other legal materials. (2006, December 13). 
Convention on the Rights of Persons with Disabilities. Retrieved February 22, 2022, from https://www.un.org/ru/documents/decl_conv/conventions/disability.shtml

4. Cook, A.M. (1998). Communication devices. In: J.G. Webster (Ed.). Encyclopedia of Medical Devices and Instrumentation. New York: John Wiley and Sons.

5. ESCS (2017, February 16). RA Government February 16, 2017, Decision N 141-N. RA KGMSN. Retrieved February 22, 2022, from https://escs.am/en/news/5020:

6. Grassman, L. (2002). Identity and Augmentative and Alternative Communication. JSET E-Journal, 17(3).

7. Handbook of Research on ICT-Enabled Transformational Government: A Global Perspective. (2011). Information Science Publishing. https://doi.org/10.4018/978-160566-390-6

8. ISAAC - Home. (n.d.). The International Society for Augmentative and Alternative Communication (ISAAC). Retrieved February 22, 2022, from https://isaaconline.org/english/home/

9. Khukhlaev, O., Chibisova, M., \& Shemanov, A. (2015). Inclusive Approach to the Integration of Migrant Children in Education. Psychological Science and Education, 20(1), 15-27. https://doi.org/10.17759/pse.2015200103

10. Shemanov, A. (2016). Digital technologies in the context of inclusion. Modern Foreign Psychology, 5(3), 66-74. https://doi.org/10.17759/jmfp.2016050307

11. Sigafoos, J. \& O'Reilly, M.F. (2004). Providing the means for communicative ends: introduction to the special issue on Augmentative Alternative Communication. Disability \& Rehabilitation, 26 (21-22), (pp. 1229-1230). 